\title{
Evaluation of SARS-CoV-2 spike antibody levels among Sputnik V first dose vaccinated people in Pakistan: formulation of national anti-COVID-19 mass vaccination strategy.
}

Umar Saeed ( $\sim$ umarsaeed15@yahoo.com )

Islamabad Diagnostic Center Pakistan

Sara Rizwan Uppal

Islamabad Diagnostic Center Pakistan

Zahra Zahid Piracha

Islamabad Diagnostic Center Pakistan

Aftab Ahmad Khan

Islamabad Diagnostic Center Pakistan

Azhar Rasheed

Islamabad Diagnostic Center Pakistan

Amir Waheed

Islamabad Diagnostic Center Pakistan

Rehan Uppal

Islamabad Diagnostic Center Pakistan

Rizwan Uppal

Islamabad Diagnostic Center Pakistan

\section{Research Article}

Keywords: SARS-CoV-2, COVID-19, Rapid diagnostic testing, Nasopharyngeal swab, Saliva, real-time PCR

Posted Date: May 6th, 2021

DOI: https://doi.org/10.21203/rs.3.rs-480406/v1

License: (c) (i) This work is licensed under a Creative Commons Attribution 4.0 International License. Read Full License 


\section{Abstract}

Rapid ramp up of immune responses against SARS-CoV-2 during pandemic enables adequate prevention and treatment for COVID-19. Estimating levels of SARS-CoV-2 spike protein antibodies post vaccination is crucial for designing mass-vaccination strategies. The aim of this study was to evaluate effectiveness of Sputnik V first dose in Pakistan. A cross-sectional study of 2000 participants was conducted for examining Gam-COVID-Vac or Sputnik V first dose effects at 21st days post administration at Islamabad Diagnostic Center, Islamabad, Pakistan. From 100 real-time PCR negative (SARS-CoV-2 RNA) individuals, samples were collected and analyzed for antibodies to the SARS-CoV-2 spike protein using Electro-chemiluminescence immunoassay (ECLIA) (Elecsys \# 09289267190 Roche, USA). 85\% of the participants showed strong positive results with SARS-CoV-2 spike protein antibodies $>1.5 \mathrm{AU} / \mathrm{ml}$. The individuals with antibody titer $>$ $250 \mathrm{AU} / \mathrm{ml}$ were $34.9 \%$. Among those with antibody levels $>250 \mathrm{AU} / \mathrm{ml} 52 \%$ had previous history of COVID19 infection. While participants with $>100 \mathrm{AU} / \mathrm{ml}$ of antibodies were $12.7 \%$. However $9.5 \%$ showed antibody titer of $>25 \mathrm{AU} / \mathrm{ml}$. $27 \%$ of participants had antibody titers of $>1.5-2.5 \mathrm{AU} / \mathrm{ml}$. While antibody titers of $<1.5$ $\mathrm{AU} / \mathrm{ml}$ were observed among $15.9 \%$ of participants. Majority of the individuals represented significantly high antibody titers against SARS-CoV-2 even before second booster dose of Ad5 based Sputnik V vaccine. Continuous monitoring of antibody levels among COVID-19 vaccinated populations are deemed to assess humoral immunity status against SARS-CoV-2 infections.

\section{Introduction}

Severe acute respiratory syndrome (SARS) coronavirus 2 (SARS-CoV-2), a novel positive-strand RNA coronavirus of Coronaviridae family, is responsible for causing devastating COVID-19 pandemic causing millions of deaths across the globe (1).SARS-CoV-2 genome contains non-structural and structural proteins including envelope (E), membrane (M), and nucleocapsid $(N)$ and spike (S). DuringSARS-CoV-2course of infection, the $S$ glycoproteins interacts with angiotensin converting enzyme 2 (ACE2) across the epithelial Alveolar type 2 progenitor (AT2) cells and regulate multiple intracellular biochemical mechanisms and pathways to favor viral pathogenesis (2).

To date, majority of COVID-19 vaccine strategies aim to induce neutralizing antibodies against $S$, therefore blocking SARS-CoV-2early-stage infection (3). According to WHO, globally 63 candidate vaccines are in human clinical trials, while more than 172 candidates are in preclinical development stages (4). Among major COVID-19 vaccines in developmental stage only Gam-COVID-Vac or Sputnik V utilized heterologous (adenovirus 5 and adenovirus 26) prime-boost recombinant adenovirus approach given 21 days apart (to overcome any pre-existing adenovirus immunity) responsibly provoked humoral and cellular immune response among $98 \%$ and $100 \%$ volunteers, respectively $(5,6)$.

Post-intramuscular injection of Sputnik V, the replication deficient Ad26 and Ad5 penetrate to host cells and deliver recombinant DNA into the nucleus to stimulate transcription via synthesizing mRNAs translated into spike proteins that migrate onto cell surface. The vaccinated cells may break spike proteins into fragments. Afterwards, protruding spikes or spike protein, recognized by the immune system induces strong immune responses to kill vaccinated cell. However, the cell debris containing spike proteins or fragments are taken 
up by antigen-presenting cell (APC), which presents fragments of the spike protein on its surface. Upon encounter with helper $T$ cells, the $B$ cells are activated that starts proliferation to generate antibodies against $S$ to prevent wild type SARS-CoV-2 infection. The APC can also activate killer T lymphocytes to destroy SARS-CoV-2 infected cells displaying S protein fragments on their surfaces (7).

The Phase III clinical trial results of Gamaleya Research Institute Russia on 19,866 volunteers who received Gam-COVID-Vac or Sputnik V revealed strong efficacy, immunogenicity and safety results. The efficacy result of Sputnik V against COVID-19 was $97.6 \%$ and no serious adverse events related to the vaccine were recorded $(8,9)$. Among Sputnik $V$ vaccinated volunteers, the virus neutralizing antibodies level were 1.3-1.5 times higher than level of antibodies who recovered from wild typeSARS-CoV-2 infection (6). In context of COVID-19 vaccines, it is precisely these neutralizing antibodies which are of paramount importance. Reliable quantification of the antibody responses is critical for estimating the time of protection or possible vaccine related failures.

Depending upon SARS-CoV-2 global burden of continuously increasing COVID-19, there is a dire need for mass vaccination worldwide. In resources limited low-income countries like Pakistan, healthcare system is fragile and detection of the neutralizing antibodies against SARS-CoV-2 might be crucial in formulating new vaccination strategies to curtail unprecedented COVID-19 epidemics. To date, 0.8 million people have been infected with COVID-19 in Pakistan and caused deaths in 16,999 individuals. As of 21 April 2021, 1,548,714 vaccine doses have been administered among general public (10). We aimed to evaluate SARS-CoV-2 spike antibody levels among Sputnik $V$ vaccinated group of individuals in Pakistani population.

\section{Material And Methods}

To investigate SARS-CoV-2 spike antibody response to vaccination in Pakistani populations, a crosssectional study was conducted on 2000 participants enrolled for Gam-COVID-Vac or Sputnik V (Gamaleya National Research Center, Russia) vaccination after first dose of Ad26-based vaccine. From 100 anti-SARSCoV-2 real-time PCR negative cases, respective clinical samples were obtained at $21^{\text {st }}$ day by trained personnel at Islamabad Diagnostic Center (IDC G8 branch specialized center for COVID-19), Islamabad, Pakistan. All subjects were informed prior to examination and written consent was obtained.

Quantitative determination of antibodies to the SARS-CoV-2 spike protein was based upon double-antigen sandwich assay principle using Electro-chemiluminescence immunoassay (ECLIA) (Elecsys \# 09289267190 Roche, USA). The samples were incubated with biotinylated and ruthenylated RBD antigen, followed by addition of streptavidincoated microparticles, and transferred to the measuring cell, where microparticles are magnetically captured onto the surface of the electrode. The Electrochemiluminescence is later on induced by providing voltage and measured via photomultiplier. Test kits were placed according to manufacturer's instructions. Ethical approval was obtained from all participants included in this study. This study was approved by institutional review board of IDC Pakistan.

\section{Results}


A total of 100 participants were enrolled in the study. Of these, real-time PCR negative (for SARS-CoV-2 RNA) cases were pre-selected for evaluation of SARS-CoV-2 spike protein antibody levels on 21 days after $1^{\text {st }}$ dose administration. Among selected subjects, $58.8 \%$ were males and $41.2 \%$ were females. The mean age was 45 years (range 18-60). The ECLIA analysis revealed SARS-CoV-2 spike antibody titers among enrolled participants. $85 \%$ of the participants showed strong positive results of SARS-CoV-2 spike protein antibodies $>1.5 \mathrm{AU} / \mathrm{ml}$. It was shown that $>250$ (in arbitrary units, $\mathrm{AU} / \mathrm{ml}$ ) antibody titer occurred among $34.9 \%$ of the participants. Among individuals with $>250 \mathrm{AU} / \mathrm{ml}$ antibody levels, $52 \%$ individuals had previous history of COVID-19 infection. The individuals with antibody titer $>100 \mathrm{AU} / \mathrm{ml}$ were $12.7 \%$. And $9.5 \%$ showed antibody titer of $>25 \mathrm{AU} / \mathrm{ml}$. However, $27 \%$ of the individuals constituted antibody titers of $>1.5-2.5 \mathrm{AU} / \mathrm{ml}$. While antibody titers of $<1.5 \mathrm{AU} / \mathrm{ml}$ were observed among $15.9 \%$ participants (As shown in Figure 1). Overall, it can be inferred that majority of the individuals represented significantly higher antibody titers against SARS-CoV-2 even before second booster dose of Ad5 based Sputnik V vaccine. The sensitivity of ECLIA was $98.8 \%$ (95\% Cl: $98.1-99.3 \%)$. And the diagnostic assay showed no cross reactivity against MERS-CoV, common cold, coronavirus HKU1, NL63, 229E, OC43, or other potentially cross-reactive samples.

\section{Discussion}

In Pakistan, the population exceeds 223.9 million and literacy rate is relatively lower $(11,12)$. Viral infections are on its surge (13-18). The vaccine coverage is not successful in Pakistan, due to two major reasons; including limited procurement or supply of vaccine and other might be generalized conspiracy theories, which are also prevalent across the globe. In Pakistan, majority of the people are willing to get benefit from the vaccine preventable COVID-19. However, huge demand of anti-SARS-CoV-2 vaccine supply from manufacturing companies has put a large gap across under-developed countries.

Vaccine hesitancy is integral, underlying factor linked with sporadic proliferation of viruses worldwide. Although education level is lower but awareness about vaccination is shown by the fact that people are willing to pay the actual price of vaccine (which is approximately $70 \$$ ). Due to utmost support of Pakistan Armed Forces, efficient smart lock down policies and implementation of standard operating procedures by National Command Operation Center (NCOC) of Pakistan, the expected number of deaths (80,000 per day), predicted by Medical Research Council Centre for Global Infectious Disease Analysis, Imperial College London, were efficiently reduced during first wave of COVID-19 in Pakistan (19). Several countries across the globe and WHO also appreciated smart policies implemented by Government of Pakistan to control COVID-19 first wave in Pakistan. Currently there are several multi-variant strains of SARS-CoV-2 spreading across the nation, and several deaths are being reported from neighbor country India. During the need of hour, China and Russia outreached and joined hands in support of vaccine supply under GovernmentGovernment (G/G) or Government-Business (G/B) schemes, to facilitate mass vaccination in Pakistan.

The immune responses to Sputnik $V$ vaccine were analyzed among 602 healthcare personnel volunteers from Tucumán-Argentina. It was interesting to know that among subjects with prior COVID-19 history of infection significantly strong immune response after a single vaccine dose were elicited (20). Similarly another study conducted in United States of America among 110 study participants with or without preexisting SARS-CoV-2 immunity, vaccinated with Pfizer and Moderna COVID-19 vaccines, revealed that after 
the first dose of administration the antibody titers with preexisting immunity were around 10 to 45 times as high as those of vaccines without preexisting immunity (21). In contrast to other vaccines with two doses, the Sputnik V is adenoviral (serotypes 5 and 26) based recombinant DNA vaccine, in which antigen insert is an unmodified full-length S-protein (22). In current study among volunteers from Pakistan origin, the SARSCoV-2 real time PCR negative volunteers were pre-selected for the analysis. Majority of the individuals presented notably higher anti-SARS-CoV-2 antibody levels of $>250 \mathrm{AU} / \mathrm{ml}$. Among those with antibody levels $>250 \mathrm{AU} / \mathrm{ml} 52 \%$ had previous history of COVID-19 infection. Generally among two dosage vaccines, the ramp up of immunity after first dose is rare. However, the Sputnik $V$ has interestingly and amazingly aroused ramp up immunity among majority of enrolled participants even after the first dose of administration, which can further affirm the efficacy of the vaccine in Pakistani population. Current study is important not only for policy making strategic organizations at national level but also demonstrate need for accurate determination of SARS-CoV-2 spike antibody levels among vaccinated group of individuals across the world.

\section{Conclusion}

Evaluation of neutralizing antibodies levels post vaccination is very helpful to determine level of humoral immunity, after vaccination, although cellular immunity cannot be evaluated in clinical laboratory. Herein, we demonstrated for the first time that among Sputnik $V$ vaccinated group, prior to second dose administration, the SARS-CoV-2 spike antibodies levels were significantly high which indicates promising results for immunization against COVID-19. Based upon this study, it can be speculated that after the second dose administration of Sputnik V, the SARS-CoV-2 spike antibody levels will further ramp up significantly to immunize against COVID-19. Also quick immunity with $1^{\text {st }}$ dose gives Sputnik $V$ an edge over other vaccines, which can be useful at a time when virus spread is fast and many patients get infected before second dose of other vaccines.

\section{List Of Abbreviations}

SARS-CoV-2: Severe Acute Respiratory Syndrome Coronavirus 2

WHO: World Health Organization

MERS-CoV: Middle East Respiratory Syndrome Coronavirus

ECLIA: Electro-chemiluminescence immunoassay

APC: antigen-presenting cell

NCOC: National Command Operation Center

ACE2: Angiotensin-Converting Enzyme 2

AT2: Alveolar type 2 progenitor 
PCR: Polymerase Chain Reaction

\section{Declarations}

Ethics approval and consent to participate:

The study has been approved by ethical review board of Islamabad Diagnostic Center Pakistan, and informed patients concern was obtained.

\section{Consent to publication:}

All authors approved the submission of the manuscript for publication

\section{Availability of data and material:}

The data is available and can be used for the academic or research purposes.

\section{Competing interests:}

The authors have no conflict of interest.

\section{Funding:}

No funding was allotted for this study

\section{Authors Contribution:}

RiU is principal investigator of the study. RiU and US conceived the study, US wrote manuscript and analyzed data and Co-PI of the study; ZZP assisted in manuscript writing and analysis, SRU, AAK, AR, AW, and ReU performed the experiments and helped in data analysis.

\section{Acknowledgements:}

We acknowledge the kind efforts of IDC staff for discussions and improvements in the study.

\section{References}

1. Coronavirus disease 2019 (COVID-2019): situation report. Geneva: World Health Organization, 2021. Available at [https://www.who.int/emergencies/diseases/novel-coronavirus-2019? gclid=CjwKCAjwg4EBhBwEiwAzYAlskKcrAbaObdgRFpjNRC4cj9C3pBEQLTW3ZRjfiozKkUCfbUeYP6N8xoCDPAQAvD_BwE].

2. Saeed, U., Uppal, S.R., Piracha, Z.Z. et al. Evaluation of SARS-CoV-2 antigen-based rapid diagnostic kits in Pakistan: formulation of COVID-19 national testing strategy. Virol J 18, 34 (2021).

3. Spotlight on COVID-19: vaccine development. InvivoGen https://www.invivogen.com/spotlight-covid19-vaccine-development (2020). 
4. Draft landscape of COVID-19 candidate vaccines. Available online [https://www.who.int/publications/m/item/draft-landscape-of-covid-19-candidate-vaccines (World Health Organization, 2020)].

5. Barouch DH, Kik SV, Weverling GJ, et al.International seroepidemiology of adenovirus serotypes 5, 26, 35, and 48 in pediatric and adult populations.Vaccine. 2011; 29: 5203-5209.

6. Logunov DY, Dolzhikova IV, Shcheblyakov DV, Tukhvatulin Al, Zubkova OV, Dzharullaeva AS, Kovyrshina AV, Lubenets NL, Grousova DM, Erokhova AS, Botikov AG, Izhaeva FM, Popova O, Ozharovskaya TA, Esmagambetov IB, Favorskaya IA, Zrelkin DI, Voronina DV, Shcherbinin DN, Semikhin AS, Simakova YV, Tokarskaya EA, Egorova DA, Shmarov MM, Nikitenko NA, Gushchin VA, Smolyarchuk EA, Zyryanov SK, Borisevich SV, Naroditsky BS, Gintsburg AL; Gam-COVID-Vac Vaccine Trial Group. Safety and efficacy of an rAd26 and rAd5 vector-based heterologous prime-boost COVID-19 vaccine: an interim analysis of a randomised controlled phase 3 trial in Russia. Lancet. 2021 Feb 20;397(10275):671-681. doi: 10.1016/S0140-6736(21)00234-8. Epub 2021 Feb 2. Erratum in: Lancet. 2021 Feb 20;397(10275):670. PMID: 33545094; PMCID: PMC7852454.

7. Corum J and Zimmer C. How Gamaleya's Vaccine Works. Available online [https://www.nytimes.com/interactive/2021/health/gamaleya-covid-19-vaccine.html].

8. Jones I, Roy P. Sputnik V COVID-19 vaccine candidate appears safe and effective. Lancet. 2021 Feb 20;397(10275):642-643. doi: 10.1016/S0140-6736(21)00191-4. Epub 2021 Feb 2. PMID: 33545098; PMCID: PMC7906719.

9. Pharmaceutical Technology News. Russia's Sputnik V Covid-19 vaccine shows $97.6 \%$ efficacy. Available online via [https://www.pharmaceutical-technology.com/news/russia-sputnik-v-efficacy/]

10. WHO COVID-19 Country Status 2021. Available online via [https://covid19.who.int/region/emro/country/pk]

11. Pakistan Population 2021. [https://www.worldometers.info/world-population/pakistan-population/]

12. Education in Pakistan 2021. [https://en.wikipedia.org/wiki/Education_in_Pakistan]

13. Saeed U, Uppal SR, Piracha ZZ, Uppal R. COVID-19 transmission via fomites at low temperature: A potential silent SARS-CoV-2 propagation route. Am J Biomed Sci \& Res. 2021;12(1):80-2.

14. Saeed U, Uppal SR, Piracha ZZ, Khan AA, Rasheed A, Zaheer H, et al. Effectivity analysis of SARS-CoV-2 nasopharyngeal swab rapid testing kits in Pakistan: A scenario of inadequate COVID-19 diagnosis. Research Square. 2021. doi: 10.21203/rs.3.rs-315851/v1

15. Saeed U, Kim J, Piracha ZZ, Kwon H, Jung J, Chwae YJ, Park S, Shin HJ, Kim K. Parvulin 14 and Parvulin 17 Bind to HBx and cccDNA and Upregulate Hepatitis B Virus Replication from cccDNA to Virion in an HBx-Dependent Manner. J Virol. 2019 Mar 5;93(6):e01840-18. doi: 10.1128/JVI.01840-18. PMID: 30567987; PMCID: PMC6401437.

16. Piracha ZZ, Kwon H, Saeed U, Kim J, Jung J, Chwae YJ, Park S, Shin HJ, Kim K. Sirtuin 2 Isoform 1 Enhances Hepatitis B Virus RNA Transcription and DNA Synthesis through the AKT/GSK-3 $\beta / \beta$-Catenin Signaling Pathway. J Virol. 2018 Oct 12;92(21):e00955-18. doi: 10.1128/JVI.00955-18. PMID: 30111572; PMCID: PMC6189494. 
17. Piracha ZZ, Saeed U, Kim J, Kwon H, Chwae YJ, Lee HW, Lim JH, Park S, Shin HJ, Kim K. An Alternatively Spliced Sirtuin 2 Isoform 5 Inhibits Hepatitis B Virus Replication from cccDNA by Repressing Epigenetic Modifications Made by Histone Lysine Methyltransferases. J Virol. $2020 \mathrm{Jul}$ 30;94(16):e00926-20. doi: 10.1128/JVI.00926-20. PMID: 32493816; PMCID: PMC7394897.

18. Saeed U, Piracha ZZ, Manzoor S. Hepatitis $C$ virus induces oxidative stress and DNA damage by regulating DNAPKCs, ATM, ATR and PARP mediated signaling and guards cell from cancerous condition by upregulating RB, P53 and downregulating VEGF. Acta Virol. 2017;61(3):316-323. doi: 10.4149/av_2017_310. PMID: 28854796.

19. The International News $28^{\text {th }}$ April 2020. $2.229 \mathrm{~m}$ people to die in Pakistan if lockdown not imposed? Available online [https://www.thenews.com.pk/print/672563-2-229m-people-to-die-in-pakistan-iflockdown-not-imposed].

20. Chahla RE, Tomas-Grau RH, Cazorla SI et al., Past SARS-CoV-2 infection elicits a strong immune response after a single vaccine dose. MedRixV pre-print. DOI: 10.1101/2021.03.14.21253039.

21. Krammer F, Srivastava K, Alshammary H, Amoako AA, Awawda MH, Beach KF, Bermúdez-González MC, Bielak DA, Carreño JM, Chernet RL, Eaker LQ, Ferreri ED, Floda DL, Gleason CR, Hamburger JZ, Jiang K, Kleiner G, Jurczyszak D, Matthews JC, Mendez WA, Nabeel I, Mulder LCF, Raskin AJ, Russo KT, Salimbangon AT, Saksena M, Shin AS, Singh G, Sominsky LA, Stadlbauer D, Wajnberg A, Simon V. Antibody Responses in Seropositive Persons after a Single Dose of SARS-CoV-2 mRNA Vaccine. N Engl J Med. 2021 Apr 8;384(14):1372-1374. doi: 10.1056/NEJMc2101667. Epub 2021 Mar 10. PMID: 33691060; PMCID: PMC8008743.

22. Sputnik V Vaccine 2021. Access on 2021-04-27. Available online via [https://www.precisionvaccinations.com/vaccines/sputnik-v-vaccine].

\section{Figures}




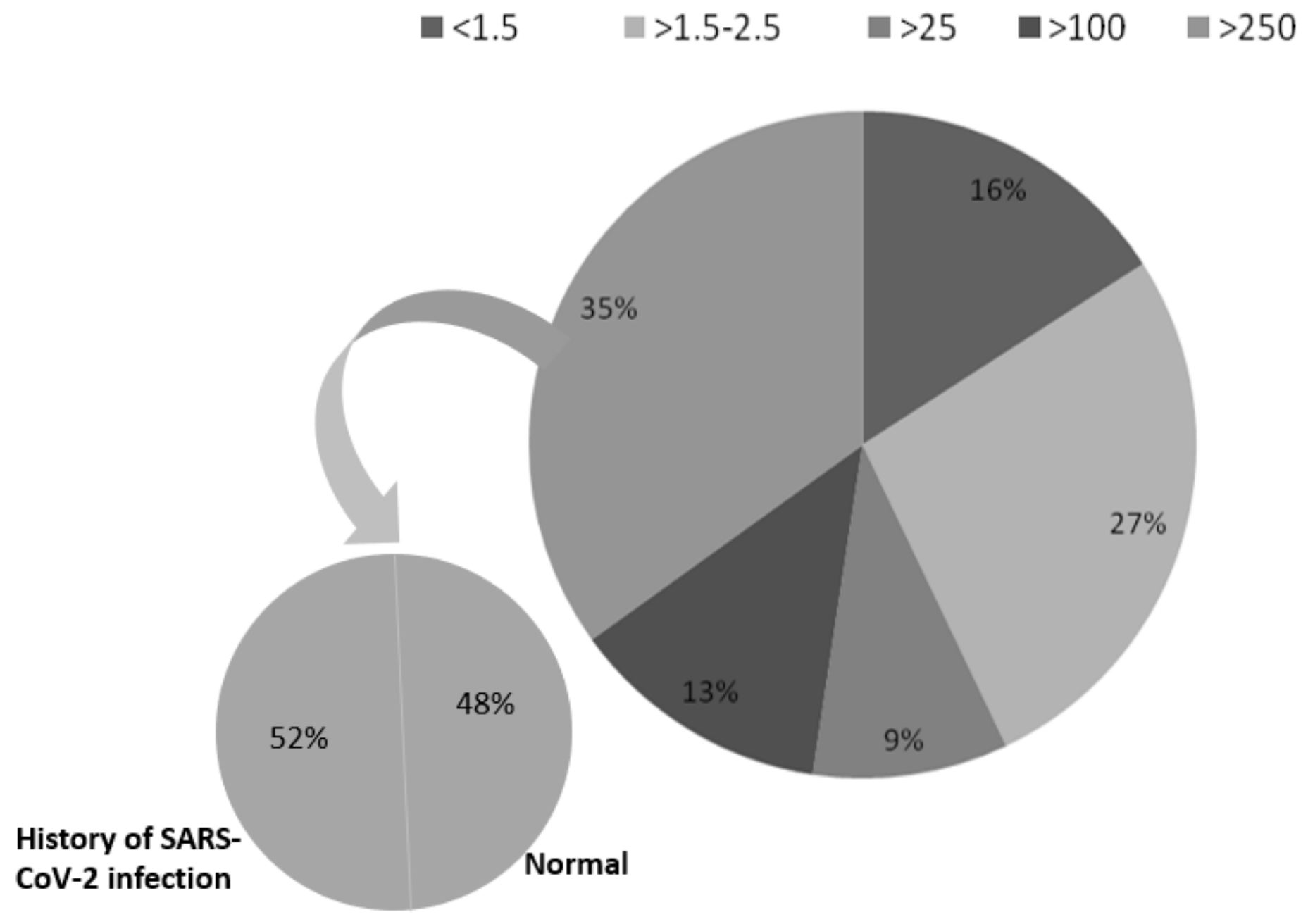

SARS-CoV-2 Spike antibody levels (AU/ml)

Figure 1

Prevalence of neutralizing antibodies against SARS-COV-2 spike protein among Sputnik $V$ first dose vaccinated. 